\title{
Obesity, lifestyle behaviors and dyslipidemia among Chinese adults aged 45 and older
}

Pengtao Liu ( $\square$ lpt1978@126.com )

Weifang Medical University https://orcid.org/0000-0003-0190-0935

\section{Yinghui You}

Weifang Medical University

Qinghui Meng

Weifang Medical University

Chunhua Tian

Sichuan Center for diseases Control and Prevention

Junjie Wang

Chineses Center for Disease Control and Prevention

\section{Guifeng Ma}

Weifang Medical University

\section{Research article}

Keywords: Dyslipidemia, lifestyle behaviors, obesity, China.

Posted Date: December 2nd, 2019

DOl: https://doi.org/10.21203/rs.2.17925/v1

License: (c) (i) This work is licensed under a Creative Commons Attribution 4.0 International License.

Read Full License 
Obesity, lifestyle behaviors and dyslipidemia among Chinese adults aged 45 and older

Yinghui You ${ }^{1}$, Qinghui Meng ${ }^{1}$, Chunhua Tian², Junjie Wang ${ }^{3}$, Guifeng Ma ${ }^{1}$ and Pengtao Liu ${ }^{1}$

${ }^{1}$ Weifang Medical University, Weifang, Shandong Province, China

${ }^{2}$ Sichuan Center for Disease Control and Prevention, Chengdu, Sichuan, China

${ }^{3}$ Chinese Center for Disease Control and Prevention, Beijing, China

\section{Correspondence to:}

Pengtao Liu,

Department of General Courses, Weifang Medical University, No. 7166 Baotong West Street, Weicheng District, Weifang 261053, Shandong Province, China

lpt1978@126.com

Or

Guifeng Ma,

Department of General Courses, Weifang Medical University, No. 7166 Baotong West Street, Weicheng District, Weifang 261053, Shandong Province, China

maguifeng10@126.com

Yinghui You, yyhihy@126.com

Qinghui Meng, hui_m12@163.com 
Chunhua Tian,358765644@qq.com

Junjie Wang jjw405047@163.com

Guifeng Ma, maguifeng10@126.com

Pengtao Liu, lpt1978@126.com 


\begin{abstract}
Background

This study investigated the importance of obesity and lifestyle behaviors in affecting dyslipidemia among adults aged 45 and older in China. The strength of our study is in using the decision tree model to clearly rank the importance of those key factors affecting dyslipidemia.
\end{abstract}

\title{
Methods
}

Data were taken from the China Health and Retirement Longitudinal Study. A total of 9,038 adults were included in the study. Logistic regression was used to examine the associations between obesity, lifestyle behaviors and dyslipidemia. Decision tree was built to select the best scheme on prevention of dyslipidemia.

\section{Results}

Based on body mass index (BMI), 33.98\% of Chinese age $\geq 45$ years old were overweight and a further $12.73 \%$ were obese. Logistic regression analysis showed that participants who were obese (AOR 6.82, 95\% CI 3.67-12.37, P<0.0001), with hypertension stage 2 (1.53, 1.23-1.90, $\mathrm{P}=0.0001)$ and lived in main city zone $(2.68,2.22-3.22, \mathrm{P}<0.0001)$ were more likely to have dyslipidemia; Participants who usually took part in vigorous activity $(0.66,0.54-0.80$, $\mathrm{P}<0.0001$ ) or did moderate/light activity more than 2 hours one day (moderate: $0.66,0.53-0.84$, $\mathrm{P}=0.0005$; light: $0.79,0.65-0.97, \mathrm{P}=0.0231$ ) were less likely to have dyslipidemia. Decision tree analysis showed that enhancing physical activity could effectively reduce the rate of dyslipidemia among people with overweight or obesity.

\section{Conclusions}


Overweight and obesity are rapidly growing threats in China. Regular physical activity could positively affect dyslipidemia and produce desirable health status. This will be beneficial evidence for educating those who do not or cannot perform regular and substantial physical activities.

\section{Keywords}

Dyslipidemia, lifestyle behaviors, obesity, China. 


\section{Background}

Over the past two decades, Chinese people have experienced the living environment and unsatisfactory lifestyle changes, such as reduced physical activity, more stressed and long-term sedentary work (1-4). Accordingly, the prevalence of overweight and obesity are rapidly increasing in China $(5,6)$. Scientific research has confirmed that overweight and obesity is an important risk factor to induce dyslipidemia, and dyslipidemia plays an important role in the formation and development of cardiovascular diseases (CVDs) (7-9).

Dyslipidemia as a major risk factor for CVDs has aroused Chinese people's big awareness (7, 8), but treatment of dyslipidemia has not improved a lot accordingly in China $(10,11)$. A cross sectional study involving 25,697 Chinese individuals found that $38.5 \%$ of those receiving lipid lowering treatment did not achieve the treatment goal for low density lipoprotein, which is similar to the results of other studies from China (12-14). Previous research found that lifestyle changes including increased physical activity and decreased body mass index (BMI) had profound effects on preventing dyslipidemia (15-18). These findings, together with ones from observational and clinical studies, suggested that combination therapy in controlling dyslipidemia was very important; no obesity and healthy lifestyle behavior would be focused to help the treatment of dyslipidemia $(16,19-22)$.

Physical activity has been recommended in the prevention of obesity and dyslipidemia by health organizations around the world, because it costs less and generates fewer side effects than isolated medicine $(20,23)$. Most studies on prevention of dyslipidemia adopted the traditional statistical methods and the interaction between demographic characteristics, lifestyle behaviors and dyslipidemia has rarely been incorporated into the research $(17,24,25)$. Moreover, few 
information was available regarding levels of physical activity done by the elderly in China. The intensity as well as frequency and duration of physical activities was frequently overlooked or unknown by elderly patients with obesity and dyslipidemia in China $(26,27)$. It is needed to compare the existing schemes in preventing obesity and dyslipidemia, select the best one, and make it optimized. Accordingly, this study presents national-level data from 2015 China Health and Retirement Longitudinal Study (CHARLS) to estimate the relationship between obesity, lifestyle behaviors and dyslipidemia in middle-aged and older adults in China. Specifically, we'll be looking into the evidences in three aspects of physical activities (intensity, frequency and duration) on prevention of obesity and dyslipidemia and select the best scheme for dyslipidemia patients.

\section{Methods}

\section{Data source}

We used data from the 2015 national follow-up survey of CHARLS, which was designed to provide a high-quality nationally representative panel data with a wide range of information serving the needs of study on aging-related problems in China. The data covered information of individuals of age $\geq 45$ years, and included assessments of lifestyle behaviors, the social and economic circumstances of community residents. The CHARLS team created separate crosssectional weights for individuals corrected for non-response and sampling frame errors in each step of the CHARLS. Details of the CHARLS have been described in previous studies $(28,29)$. A total of 9,038 men and women aged 45 or older were involved in the study. Face-to-face interviews at participants' home monitored how their health changed over time and how they adjusted to these changes. The presence of dyslipidemia and physical exercise practice were calculated according to self-reported information through household interviews. 


\section{Definitions}

Body mass index (BMI) was calculated as weight in $\mathrm{kg} / \mathrm{height} \mathrm{t}^{2}$ in $\mathrm{m}^{2}$, and was categorized as $<18.5 \mathrm{~kg} / \mathrm{m}^{2}$ (underweight), $18.5-24 \mathrm{~kg} / \mathrm{m}^{2}$ (normal weight), $24-28 \mathrm{~kg} / \mathrm{m}^{2}$ (overweight) or $\geq 28$ $\mathrm{kg} / \mathrm{m}^{2}$ (obese) (30). The prevalence of dyslipidemia depended on whether the respondent reported having certain health conditions (includes: elevation of low-density lipoprotein, triglycerides, and total cholesterol, or a low high-density lipoprotein level.) in a previous interview and/or confirmed them in the last interview via a structured questionnaire. Vigorous activities were considered as making breath much harder than normal and might include heavy lifting, digging, plowing, aerobics, fast bicycling, and cycling with a heavy load. Moderate physical activities were considered as making breath somewhat harder than normal and might include carrying light loads, bicycling at a regular pace, or mopping the floor. Light physical activities were considered as making breath normal, such as walking from place to place that you might do solely for recreation, exercise, or leisure.

\section{Statistical analysis}

Statistical analysis was performed using R software (Version 3.4.1, https://www.r-project.org/) and considered the sample weights and complex survey design of the CHARLS. The significant differences in categorical variables were analyzed using chi-square test. All prevalence rates were weighted with the cross-sectional biomarker weight which was based on the individual one and a logit regression of whether the individual responses in biomarker. Based on the statistically significant associations provided by the chi-square test, logistic regression was used to examine the lifestyle factors related to the development of dyslipidemia. The results of logistic regression models were presented as odds ratios (OR), adjusted odds ratios (AOR) and 
$95 \%$ confidence interval $(\mathrm{CI})$. All statistical tests were two-tailed and $\mathrm{P} \leq 0.05$ was considered statistically significant.

Decision tree model was established to analyze the importance levels of physical activity on prevention of dyslipidemia. Rpart ( $\mathrm{R}$ package: recursive partitioning for classification, regression and survival trees, version 4.1-13.) was used to create the decision tree model. It was built by the following process: first the single variable was found which best split the data into two groups, and then this process was applied to each sub-group, and so on recursively until no improvement could be made or the subgroups reached a minimum size (10 for this data). The CRT growing method was used to maximize within-node homogeneity. CRT split the data into segments that were as homogeneous as possible with respect to the dependent variable $(31,32)$. Gini method was used to measure impurity and the minimum decrease in impurity required to split nodes. The Gini impurity measure at a node $t$ was defined as:

$$
\mathrm{i}(\mathrm{t})=\sum_{i, j} C(i \mid j) p(i \mid t) p(j \mid t)
$$

The Gini splitting criterion was the decrease of impurity defined as:

$$
\Delta \mathrm{i}(\mathrm{s}, \mathrm{t})=\mathrm{i}(\mathrm{t})-P_{L} i\left(t_{L}\right)-P_{R} i\left(t_{R}\right)
$$

where $P_{L}$ and $P_{R}$ were probabilities of sending a case to the left child node $t_{L}$ and to the right child node $t_{R}$ respectively. They were estimated as $P_{L}=P\left(t_{L}\right) / p(t)$ and $P_{R}=P\left(t_{R}\right) / p(t)$. The minimum decrease in impurity required to split a node was set to 0.0001 . Cross validation was used to assess how well the tree structure generalized to a larger population, and the number of sample folds was set to 10 . The cross validated risk estimate for the final tree was calculated as the average of the risks for all of the trees. An overall measure of variable importance was by comparing the goodness of split measures for each variable (33). 


\section{Results}

Table 1 presents the self-reported dyslipidemia rate of the study participants stratified by demographic characteristics and lifestyle behaviors. Based on BMI, 33.98\% of Chinese age $\geq$ 45 were overweight and a further $12.73 \%$ were obese. Overweight participants $(\mathrm{BMI} \geq 24)$ had a dyslipidemia rate that was almost twice higher than that of normal or light weight. Similarly, individuals with higher blood pressure and those who lived in main city zone had higher rates of dyslipidemia. On the other hand, participants with light-to-moderate alcohol consumption, adequate sleep, and those who had more physical activities had lower rates of dyslipidemia (Table 1).

Table 1. The dyslipidemia rate of the study participants $(n=9038)$.

Table 2 shows the results of logistic regression models describing the association between lifestyle behaviors especially physical activities and dyslipidemia. After adjusting for demographics, behavioral risks, and current residence, participants who were obese (BMI $\geq 28$ $\left.\mathrm{kg} / \mathrm{m}^{2}\right)(\mathrm{AOR} 6.82,95 \%$ CI 3.67-12.37, $\mathrm{P}<0.0001)$, high blood pressure/stage $2(1.53,1.23-$ $1.90, \mathrm{P}=0.0001)$ and lived in main city zone $(2.68,2.22-3.22, \mathrm{P}<0.0001)$ were more likely to have dyslipidemia. On the other hand, participants who usually took part in vigorous activity more than 10 minutes a week $(0.66,0.54-0.80, \mathrm{P}<0.0001)$, did moderate activity more than 2 hours one day $(0.66,0.53-0.84, \mathrm{P}=0.0005)$, and did light activity more than 2 hours one day $(0.79,0.65-0.97, \mathrm{P}=0.0231)$ were less likely to have dyslipidemia (Table 2$)$. 
Table 2. Associations between lifestyle behaviors and the prevalence of dyslipidemia.

Fig. 1 shows the importance of factors on prevention of dyslipidemia analyzed by decision tree model. We take the effect of BMI, the most important factor on prevention of dyslipidemia, as normalized importance $100 \%$. By comparison, the normalized importance of days spent on vigorous activity per week was $79.0 \%$, vigorous activity over half an hour one day was $65.2 \%$, vigorous activity over 4 hours one day was $52.0 \%$, moderate activity over half an hour one day was $43.2 \%$, days spent on moderate activity per week was $26.9 \%$, light activity over 4 hours one day was $24.4 \%$, etc. Further detailed information on importance of specific types of physical activities can be found in Fig.1.

Fig.1 Variable importance on prevention of dyslipidemia.

Fig.2 shows the structure of the decision tree model. The diagram indicated that participants with BMI $<24 \mathrm{~kg} / \mathrm{m}^{2}$, not living in village, and usually taking part in vigorous physical activity 5 days every week had the lowest rate of dyslipidemia (0.0\%, Fig.2: Node 31). On the other hand, participants with $\mathrm{BMI} \geq 28 \mathrm{~kg} / \mathrm{m}^{2}$, age $\geq 55$ years old, taking part in moderate physical activity less than half an hour one day, and never taking part in vigorous physical activity during the whole week had higher prevalence of dyslipidemia (32.9\%, Fig.2: Node 18; $37.7 \%$, Node 39; and 31.9\%, Node 40). Participants with $\mathrm{BMI} \geq 28 \mathrm{~kg} / \mathrm{m}^{2}$ had better choose vigorous physical activity if their age $<55$ years old, and choose moderate or light activity to a certain extent if their age $\geq 55$ years old to prevent dyslipidemia (Fig.2: Node 12, Node 14 and Node 40). Other effective physical activity options are shown in the Fig.2. 
Fig.2 The structure of the decision tree model.

\section{Discussion}

In this nationally representative longitudinal survey among middle-aged and older adults in China, the prevalence of overweight was $33.98 \%$, and the prevalence of obesity was $12.73 \%$. Obese participants had a higher rate of dyslipidemia (20.45\%) than participants with overweight (11.24\%), normal weight (7.73\%) and underweight (3.05\%), which proved previous studies that high BMI was associated with increased dyslipidemia risk $(2,34,35)$. This study made a detailed classification on healthy lifestyle of middle-aged and older adults in China (Fig.2). Physical activity as one of healthy life behaviors played a key preventive role in dyslipidemia. This result may explain why some obese individuals do not develop dyslipidemia, while some individuals with normal weight become dyslipidemic.

Many mixed protective factors can prevent the occurrence of dyslipidemia among middle-aged and older adults. Prevention of dyslipidemia in adults with obesity can also benefit from these factors (Fig.2). The results showed that for middle-aged adults with BMI $\geq 28 \mathrm{~kg} / \mathrm{m}^{2}$, vigorous physical activity was far more effective than moderate and light activity on prevention of dyslipidemia; for older adults (age $\geq 55$ ) with BMI $\geq 28 \mathrm{~kg} / \mathrm{m}^{2}$, moderate physical activity was the better choice, while it is worth noting that 10 minutes of vigorous physical activities one week can gradually help reduce the rate of dyslipidemia in this group (Fig.2: Node 23); for adults living in main city zone, physical activity frequency seemed to be more important than the intensity to induce beneficial effects on prevention of dyslipidemia, etc. Combined with previous studies that a significant amount of weekly energy expenditure from physical activity 
could produce changes in blood lipids $(20,36)$, the targeted population would be suggested focusing on days spent on regular physical activities. But due to the individual physical difference, it is better to select personally suitable physical activity and healthy life style.

The other important variables in the tree model, according to the normalized importance, were residence, BP levels, drinking, smoking, gender, and sleep duration. This finding could support the idea that lifestyle changes could affect blood lipid levels and prevention of dyslipidemia $(37,38)$. Although some influential factors might not be comprehensively considered in the model, physical activity with multiple adjustments in life was the best option for older people. Besides the strong awareness of proper physical activity, more comprehensive strategies toward the prevention, screening, treatment, and control would be needed in China to lower the prevalence of dyslipidemia, which need further research.

There were several limitations in our study. Firstly, dyslipidemia was not diagnosed by specific blood test one by one, some patients with dyslipidemia had not been identified, and therefore the rates of dyslipidemia in this study was lower than the actual value. Secondly, the crosssectional nature of our study design prevented us from determining the direction of the association between lifestyle behaviors and prevalence of dyslipidemia.

\section{Conclusions}

However, these limitations did not considerably affect our conclusions that healthy lifestyle behaviors especially physical activities were effective on prevention of obesity and dyslipidemia. The rapidly growing threats of obesity and dyslipidemia to middle-aged and older 
adults in China will decrease. For overweight or obese elderly, regular and moderate levels of physical activity were the most effective precautionary measures; for middle-aged adults, vigorous physical activity seemed to be more important than moderate and light activity to induce beneficial effects on prevention of dyslipidemia; all in all, regular physical activity could positively affect dyslipidemia and produce desirable health status. This will be beneficial evidence for educating those who do not or cannot perform regular and substantial physical activities.

\section{Abbreviations}

BMI: Body mass index

CVDs: cardiovascular diseases

CHARLS: China Health and Retirement Longitudinal Study

OR: Odds ratio

\section{Declarations}

\section{Ethics approval and consent to participate}

Ethical approval for the study was granted by the Ethical Review Committee of Peking University. All individuals in this study provided written consent at the time of participation, and written informed consent was obtained from all study participants.

\section{Consent for publication}

Not Applicable. 


\section{Availability of data and material}

All data in CHARLS are maintained at the National School of Development of Peking University and will be accessible to researchers around the world at the study website. http://charls.pku.edu.cn/zh-CN/page/data.

\section{Competing interests}

The authors declare that they have no competing interests.

\section{Funding}

This study was supported by grants from the National Natural Science Foundation of China (71673202), and Shandong medical and health science technology development program (2017WS410). The funding body did not play a role in the design of the study, data collection, analysis, interpretation of data, and in writing the manuscript. The content is solely the responsibility of the authors.

\section{Authors' contributions}

YYH, LPT and MGF conceived and designed the study. MQH, TCH, WJJ, LPT and MGF analyzed the data. YYH and LPT wrote the paper. YYH, LPT, MQH and MGF reviewed and edited the manuscript. All authors read and approved the manuscript.

\section{Acknowledgments}

We thank the China Center for Economic Research and the National School of Development of Peking University for providing the data. We thank the editor and reviewers for their comments. 


\section{References:}

1. Patnode CD, Evans CV, Senger CA, Redmond N, Lin JS. Behavioral Counseling to Promote a Healthful Diet and Physical Activity for Cardiovascular Disease Prevention in Adults Without Known Cardiovascular Disease Risk Factors: Updated Systematic Review for the US Preventive Services Task Force. U.S. Preventive Services Task Force Evidence Syntheses, formerly Systematic Evidence Reviews. Rockville (MD)2017.

2. Nisanci Kilinc F, Cagdas DN. Diet and physical activity interventions do have effects on body composition and metabolic syndrome parameters in overweight and obese adolescents and their mothers. Turk J Pediatr. 2013;55(3):292-9.

3. Bi Y, Wang L, Xu Y, Jiang Y, He J, Zhang $M$, et al. Diabetes-related metabolic risk factors in internal migrant workers in China: a national surveillance study. Lancet Diabetes Endocrinol. 2016;4(2):125-35.

4. Erem C, Hacihasanoglu A, Deger O, Kocak M, Topbas M. Prevalence of dyslipidemia and associated risk factors among Turkish adults: Trabzon lipid study. Endocrine. 2008;34(1-3):36-51.

5. Wang Y, Mi J, Shan XY, Wang QJ, Ge KY. Is China facing an obesity epidemic and the consequences? The trends in obesity and chronic disease in China. Int J Obes (Lond). 2007;31(1):17788.

6. Zhou L, Zeng $Q$, Jin S, Cheng $\mathrm{G}$. The impact of changes in dietary knowledge on adult overweight and obesity in China. PLoS One. 2017;12(6):e0179551.

7. Li JH, Wang LM, Mi SQ, Zhang M, Li YC, Jiang Y, et al. [Awareness rate, treatment rate and control rate of dyslipidemia in Chinese adults, 2010]. Zhonghua Yu Fang Yi Xue Za Zhi. 2012;46(8):687-91.

8. Zhan Y, Zhang F, Lu L, Wang J, Sun Y, Ding R, et al. Prevalence of dyslipidemia and its association with insomnia in a community based population in China. BMC Public Health. 2014;14:1050.

9. Opoku S, Gan Y, Fu W, Chen D, Addo-Yobo E, Trofimovitch D, et al. Prevalence and risk factors for dyslipidemia among adults in rural and urban China: findings from the China National Stroke Screening and prevention project (CNSSPP). BMC Public Health. 2019;19(1):1500.

10. Pan L, Yang Z, Wu Y, Yin RX, Liao Y, Wang J, et al. The prevalence, awareness, treatment and control of dyslipidemia among adults in China. Atherosclerosis. 2016;248:2-9.

11. He W, Li Q, Yang M, Jiao J, Ma X, Zhou Y, et al. Lower BMI cutoffs to define overweight and obesity in China. Obesity (Silver Spring). 2015;23(3):684-91.

12. Zhao $S$, Wang $Y, M u Y, Y u B, Y e P, Y a n X$, et al. Prevalence of dyslipidaemia in patients treated with lipid-lowering agents in China: results of the DYSlipidemia International Study (DYSIS). Atherosclerosis. 2014;235(2):463-9.

13. Gitt AK, Drexel H, Feely J, Ferrieres J, Gonzalez-Juanatey JR, Thomsen KK, et al. Persistent lipid abnormalities in statin-treated patients and predictors of LDL-cholesterol goal achievement in clinical practice in Europe and Canada. Eur J Prev Cardiol. 2012;19(2):221-30.

14. Goodman SG, Langer A, Bastien NR, McPherson R, Francis GA, Genest JJ, Jr., et al. Prevalence of dyslipidemia in statin-treated patients in Canada: results of the DYSlipidemia International Study (DYSIS). Can J Cardiol. 2010;26(9):e330-5.

15. Montesi L, Moscatiello S, Malavolti M, Marzocchi R, Marchesini G. Physical activity for the prevention and treatment of metabolic disorders. Intern Emerg Med. 2013;8(8):655-66.

16. Zheng $\mathrm{W}$, Chen $\mathrm{Y}$, Zhao A, Xue Y, Zheng Y, Mu Z, et al. Associations of sedentary behavior and physical activity with physical measurements and dyslipidemia in school-age children: a crosssectional study. BMC Public Health. 2016;16(1):1186.

17. Zhang L, Zhang WH, Zhang L, Wang PY. Prevalence of overweight/obesity and its associations with hypertension, diabetes, dyslipidemia, and metabolic syndrome: a survey in the suburban area of Beijing, 2007. Obes Facts. 2011;4(4):284-9. 
18. Tao L, Li X, Zhang J, Liu J, Liu Y, Li H, et al. Association of commuting mode with dyslipidemia and its components after accounting for air pollution in the working population of Beijing, China. BMC Public Health. 2019;19(1):622.

19. LeBlanc AG, Janssen I. Dose-response relationship between physical activity and dyslipidemia in youth. Can J Cardiol. 2010;26(6):201-5.

20. Lira FS, Rosa Neto JC, Antunes BM, Fernandes RA. The relationship between inflammation, dyslipidemia and physical exercise: from the epidemiological to molecular approach. Curr Diabetes Rev. 2014;10(6):391-6.

21. Supiyev A, Nurgozhin T, Zhumadilov Z, Peasey A, Hubacek JA, Bobak M. Prevalence, awareness, treatment and control of dyslipidemia in older persons in urban and rural population in the Astana region, Kazakhstan. BMC Public Health. 2017;17(1):651.

22. Pettersson B, Ambegaonkar B, Sazonov V, Martinell M, Stalhammar J, Wandell P. Prevalence of lipid abnormalities before and after introduction of lipid modifying therapy among Swedish patients with dyslipidemia (PRIMULA). BMC Public Health. 2010;10:737.

23. Bohn B, Wiegand S, Kiess W, Reinehr T, Stachow R, Oepen J, et al. Changing Characteristics of Obese Children and Adolescents Entering Pediatric Lifestyle Intervention Programs in Germany over the Last 11 Years: An Adiposity Patients Registry Multicenter Analysis of 65,453 Children and Adolescents. Obes Facts. 2017;10(5):517-30.

24. Bohn B, Muller MJ, Simic-Schleicher G, Kiess W, Siegfried W, Oelert M, et al. BMI or BIA: Is Body Mass Index or Body Fat Mass a Better Predictor of Cardiovascular Risk in Overweight or Obese Children and Adolescents? A German/Austrian/Swiss Multicenter APV Analysis of 3,327 Children and Adolescents. Obes Facts. 2015;8(2):156-65.

25. Qorbani M, Kelishadi R, Farrokhi-Khajeh-Pasha Y, Motlagh M, Aminaee T, Ardalan G, et al. Association of anthropometric measures with cardiovascular risk factors and metabolic syndrome in normal-weight children and adolescents: the CASPIAN III study. Obes Facts. 2013;6(5):483-92.

26. You Y, Teng W, Wang J, Ma G, Ma A, Wang J, et al. Hypertension and physical activity in middle-aged and older adults in China. Sci Rep. 2018;8(1):16098.

27. You Y, Wang J, Teng W, Ma G, Liu P. Blood pressure and noncommunicable diseases in middle-aged and older adults in China. PLoS One. 2018;13(11):e0206635.

28. Zhao Y, Hu Y, Smith JP, Strauss J, Yang G. Cohort profile: the China Health and Retirement Longitudinal Study (CHARLS). Int J Epidemiol. 2014;43(1):61-8.

29. Ning $M$, Zhang $Q$, Yang M. Comparison of self-reported and biomedical data on hypertension and diabetes: findings from the China Health and Retirement Longitudinal Study (CHARLS). BMJ Open. 2016;6(1):e009836.

30. Chen C, Lu FC, Department of Disease Control Ministry of Health PRC. The guidelines for prevention and control of overweight and obesity in Chinese adults. Biomed Environ Sci. 2004;17 Suppl:1-36.

31. Petersen MB, Tolver A, Husted L, Tolboll TH, Pihl TH. Repeated measurements of blood lactate concentration as a prognostic marker in horses with acute colitis evaluated with classification and regression trees (CART) and random forest analysis. Vet J. 2016;213:18-23.

32. Bones VC, Molento CF. The use of a decision tree based on the rabies diagnosis scenario, to assist the implementation of alternatives to laboratory animals. Altern Lab Anim. 2016;44(2):121-8.

33. T.M Therneau and E.J Atkinson. An introduction to recursive partitioning using the rpart routines. Divsion of Biostatistics 61, Mayo Clinic, 1997.

34. Ledo DL, Suano-Souza FI, Franco M, Strufaldi MWL. Body Mass Index and Cardiovascular Risk Factors in Children and Adolescents with High Birth Weight. Ann Nutr Metab. 2018;72(4):272-8.

35. Wang B, Gao W, Lv J, Yu C, Wang S, Pang Z, et al. Physical activity attenuates genetic effects on BMI: Results from a study of Chinese adult twins. Obesity (Silver Spring). 2016;24(3):750-6. 
36. Mann S, Beedie C, Jimenez A. Differential effects of aerobic exercise, resistance training and combined exercise modalities on cholesterol and the lipid profile: review, synthesis and recommendations. Sports Med. 2014;44(2):211-21.

37. Riccardi G, Vaccaro O, Costabile G, Rivellese AA. How Well Can We Control Dyslipidemias Through Lifestyle Modifications? Curr Cardiol Rep. 2016;18(7):66.

38. Sacks FM, Katan M. Randomized clinical trials on the effects of dietary fat and carbohydrate on plasma lipoproteins and cardiovascular disease. Am J Med. 2002;113 Suppl 9B:13S-24S. 
Table 1. The weighted dyslipidemia rate of the study participants $(n=9038)$.

\begin{tabular}{|c|c|c|c|}
\hline Variables & $\% *$ & \% Dyslipidemia* & $\mathbf{P}$ \\
\hline Total & $100 \%$ & $10.40 \%$ & \\
\hline Age $(\%)$ & & & $<0.0001$ \\
\hline $45-54$ & 35.50 & 6.41 & \\
\hline $55-64$ & 33.38 & 12.13 & \\
\hline $65-74$ & 20.13 & 14.62 & \\
\hline$\geqslant 75$ & 11.00 & 10.28 & \\
\hline Gender (\%) & & & 0.2535 \\
\hline Male & 49.55 & 9.86 & \\
\hline Female & 50.45 & 10.92 & \\
\hline BMI $\left(\mathrm{kg} / \mathrm{m}^{2}\right)$ & & & $<0.0001$ \\
\hline$<18.5$ & 5.90 & 3.05 & \\
\hline $18.5-23.9$ & 47.39 & 7.73 & \\
\hline $24-27.9$ & 33.98 & 11.24 & \\
\hline$\geqslant 28$ & 12.73 & 20.45 & \\
\hline Blood pressure (BP) & & & $<0.0001$ \\
\hline Normal BP & 35.80 & 7.42 & \\
\hline Elevated BP & 15.58 & 10.28 & \\
\hline High BP/Stage 1 & 20.35 & 10.23 & \\
\hline High BP/Stage 2 & 28.28 & 13.82 & \\
\hline Smoking status (\%) & & & 0.2906 \\
\hline Never & 59.70 & 10.06 & \\
\hline Ever or current & 40.30 & 10.63 & \\
\hline Drinking frequency $(\%)$ & & & 0.0128 \\
\hline Never & 62.84 & 9.48 & \\
\hline$<1$ drink/month & 27.74 & 8.66 & \\
\hline$\geqslant 1 \mathrm{drink} / \mathrm{month}$ & 9.42 & 11.3 & \\
\hline Sleep duration & & & 0.0291 \\
\hline$<7$ h sleep & 23.30 & 10.75 & \\
\hline $7-10 \mathrm{~h}$ sleep & 66.14 & 10.98 & \\
\hline$\geqslant 10 \mathrm{~h}$ sleep & 10.57 & 8.74 & \\
\hline Residency (\%) & & & $<0.0001$ \\
\hline Main city zone & 23.01 & 19.15 & \\
\hline Others & 17.92 & 8.58 & \\
\hline Village & 59.07 & 7.54 & \\
\hline $\begin{array}{l}\text { Taking part in vigorous activity } \\
\text { more than } 10 \text { minutes a week }\end{array}$ & & & $<0.0001$ \\
\hline No & 68.85 & 11.71 & \\
\hline Yes & 31.15 & 6.28 & \\
\hline $\begin{array}{l}\text { Taking part in moderate activity } \\
\text { more than } 10 \text { minutes a week }\end{array}$ & & & 0.0339 \\
\hline No & 44.68 & 10.61 & \\
\hline Yes & 55.32 & 9.19 & \\
\hline $\begin{array}{l}\text { Taking part in light activity } \\
\text { more than } 10 \text { minutes a week }\end{array}$ & & & 0.0698 \\
\hline
\end{tabular}




\begin{tabular}{|c|c|c|c|}
\hline No & 18.61 & 10.11 & \\
\hline Yes & 81.39 & 8.75 & \\
\hline $\begin{array}{l}\text { Time usually spent doing } \\
\text { vigorous activity one day }\end{array}$ & & & $<0.0001$ \\
\hline$<2$ Hours & 21.62 & 9.68 & \\
\hline$\geqslant 2$ Hours & 78.38 & 5.26 & \\
\hline $\begin{array}{l}\text { Time usually spent doing } \\
\text { moderate activity one day }\end{array}$ & & & $<0.0001$ \\
\hline$<2$ Hours & 52.90 & 11.44 & \\
\hline$\geqslant 2$ Hours & 47.10 & 7.08 & \\
\hline $\begin{array}{l}\text { Time usually spent doing } \\
\text { light activity one day }\end{array}$ & & & $<0.0001$ \\
\hline$<2$ Hours & 64.87 & 11.57 & \\
\hline$\geqslant 2$ Hours & 35.13 & 7.90 & \\
\hline
\end{tabular}


Table 2. Associations between lifestyle behaviors and the prevalence of dyslipidemia.

\begin{tabular}{|c|c|c|c|c|}
\hline Variables & OR $(95 \%$ CI $)$ & $\mathbf{P}$ & $\operatorname{AOR}(95 \% \mathrm{CI})$ & $\mathbf{P}$ \\
\hline \multicolumn{5}{|l|}{ Age } \\
\hline $45-54$ & 1.00 & & 1.00 & \\
\hline $55-64$ & $2.02(1.69,2.41)$ & 0.0023 & $2.06(1.66,2.56)$ & 0.0009 \\
\hline $65-74$ & $2.50(2.06,3.03)$ & $<0.0001$ & $2.45(1.94,3.1)$ & $<0.0001$ \\
\hline$\geqslant 75$ & $1.67(1.31,2.15)$ & 0.8247 & $1.42(0.99,2.04)$ & 0.2560 \\
\hline \multicolumn{5}{|l|}{ Gender } \\
\hline Male & 1.00 & & 1.00 & \\
\hline Female & $1.12(0.98,1.28)$ & 0.0994 & $1.06(0.83,1.35)$ & 0.6248 \\
\hline \multicolumn{5}{|l|}{ BMI $\left(\mathrm{kg} / \mathrm{m}^{2}\right)$} \\
\hline$<18.5$ & 1.00 & & 1.00 & \\
\hline $18.5-23.9$ & $2.67(1.50,4.73)$ & 0.1236 & $2.31(1.30,4.12)$ & 0.1759 \\
\hline $24-27.9$ & $4.03(2.28,7.14)$ & 0.0023 & $2.98(1.66,5.34)$ & 0.1657 \\
\hline$\geqslant 28$ & $8.18(4.58,14.63)$ & $<0.0001$ & $6.82(3.76,12.37)$ & $<0.0001$ \\
\hline \multicolumn{5}{|l|}{ Blood pressure (BP) } \\
\hline Normal BP & 1.00 & & 1.00 & \\
\hline Elevated BP & $1.43(1.12,1.83)$ & 0.9294 & $1.21(0.93,1.57)$ & 0.8184 \\
\hline High BP/Stage 1 & $1.42(1.14,1.78)$ & 0.9881 & $1.07(0.84,1.36)$ & 0.1883 \\
\hline High BP/Stage 2 & $2.00(1.65,2.43)$ & $<0.0001$ & $1.53(1.23,1.90)$ & 0.0001 \\
\hline \multicolumn{5}{|l|}{ Sleep duration } \\
\hline$<7 \mathrm{~h}$ sleep & 1.00 & & 1.00 & \\
\hline 7-10 h sleep & $1.02(0.87,1.21)$ & 0.0922 & $0.88(0.72,1.06)$ & 0.5844 \\
\hline$\geqslant 10 \mathrm{~h}$ sleep & $0.80(0.61,1.04)$ & 0.0558 & $0.69(0.50,0.96)$ & 0.0515 \\
\hline \multicolumn{5}{|l|}{ Smoking status } \\
\hline Never & 1.00 & & 1.00 & \\
\hline Ever or current & $0.94(0.82,1.08)$ & 0.3796 & $1.13(0.89,1.43)$ & 0.3124 \\
\hline \multicolumn{5}{|l|}{ Drinking frequency } \\
\hline Never & 1.00 & & 1.00 & \\
\hline$<1 /$ month & $0.82(0.64,1.05)$ & 0.6977 & $0.92(0.69,1.22)$ & 0.9803 \\
\hline$>1 /$ month & $0.74(0.63,0.87)$ & 0.0361 & $0.84(0.67,1.04)$ & 0.2407 \\
\hline \multicolumn{5}{|l|}{ Residence } \\
\hline Village & 1.00 & & 1.00 & \\
\hline Main city zone & $2.91(2.5,3.37)$ & $<0.0001$ & $2.68(2.22,3.22)$ & $<0.0001$ \\
\hline Other & $1.15(0.94,1.41)$ & $<0.0001$ & $1.08(0.84,1.38)$ & 0.0006 \\
\hline \multicolumn{5}{|c|}{$\begin{array}{l}\text { Taking part in vigorous activity } \\
\text { more than } 10 \text { minutes a week }\end{array}$} \\
\hline No & 1.00 & & 1.00 & \\
\hline Yes & $0.51(0.43,0.60)$ & $<0.0001$ & $0.66(0.54,0.80)$ & $<0.0001$ \\
\hline \multicolumn{5}{|c|}{$\begin{array}{l}\text { Taking part in moderate activity } \\
\text { more than } 10 \text { minutes a week }\end{array}$} \\
\hline No & 1.00 & & 1.00 & \\
\hline Yes & $0.85(0.74,0.98)$ & 0.0282 & $0.99(0.84,1.18)$ & 0.9471 \\
\hline \multicolumn{5}{|c|}{$\begin{array}{l}\text { Taking part in light activity } \\
\text { more than } 10 \text { minutes a week }\end{array}$} \\
\hline No & 1.00 & & 1.00 & \\
\hline Yes & $1.17(0.98,1.41)$ & 0.0867 & $0.96(0.78,1.19)$ & 0.7248 \\
\hline \multicolumn{5}{|c|}{$\begin{array}{l}\text { Time usually spent doing } \\
\text { vigorous activity one day }\end{array}$} \\
\hline$<2$ Hours & 1.00 & & 1.00 & \\
\hline$\geqslant 2$ Hours & $0.52(0.37,0.72)$ & $<0.0001$ & $0.71(0.48,1.05)$ & 0.0830 \\
\hline \multicolumn{5}{|c|}{$\begin{array}{l}\text { Time usually spent doing } \\
\text { moderate activity one day }\end{array}$} \\
\hline$<2$ Hours & 1.00 & & 1.00 & \\
\hline$\geqslant 2$ Hours & $0.59(0.48,0.72)$ & $<0.0001$ & $0.66(0.53,0.84)$ & 0.0005 \\
\hline
\end{tabular}




\begin{tabular}{|l|c|c|c|c|}
\hline $\begin{array}{l}\text { Time usually spent doing } \\
\text { light activity one day }\end{array}$ & & & & \\
\hline $\begin{array}{c}<2 \text { Hours } \\
\geqslant 2 \text { Hours }\end{array}$ & $0.66(0.55,0.78)$ & $<0.0001$ & $0.79(0.65,0.97)$ & 0.0231 \\
\hline
\end{tabular}




\section{Figure Legends}

Fig. 1 Variable importance on prevention of dyslipidemia.

Fig. 2 The structure of the decision tree model.

Red categories indicate the prevalence of dyslipidemia and green categories indicate the prevalence of no dyslipidemia; Age (1: 45-54, 2: 55-64, 3: 65-74, 4: $\geq 75$ ); Residence (1: Main city zone, 2: Other, 3: Village); Gender (1: Male, 2: Female); BMI (1: $<18.5 \mathrm{~kg} / \mathrm{m} 2,2$ : 18.5-23.9 kg/m2, 3: 24-27.9 kg/m2,4: $\geq 28 \mathrm{~kg} / \mathrm{m} 2$ ); Blood pressure (1: Normal BP, 2: Elevated BP, 3: High BP/Stage 1, 4: High BP/Stage 2); Vigorous/moderate/light activity at least 10 minutes, vigorous/moderate/light activity over half an hour/2 hours/4 hours one day (1: Yes, 2: No); Drinking frequency (1: Never, 2: <1/month 3: $>1 /$ month); Sleep duration (1: $<7$ hours, 2: 7-10 hours, $3: \geq 10$ hours). 


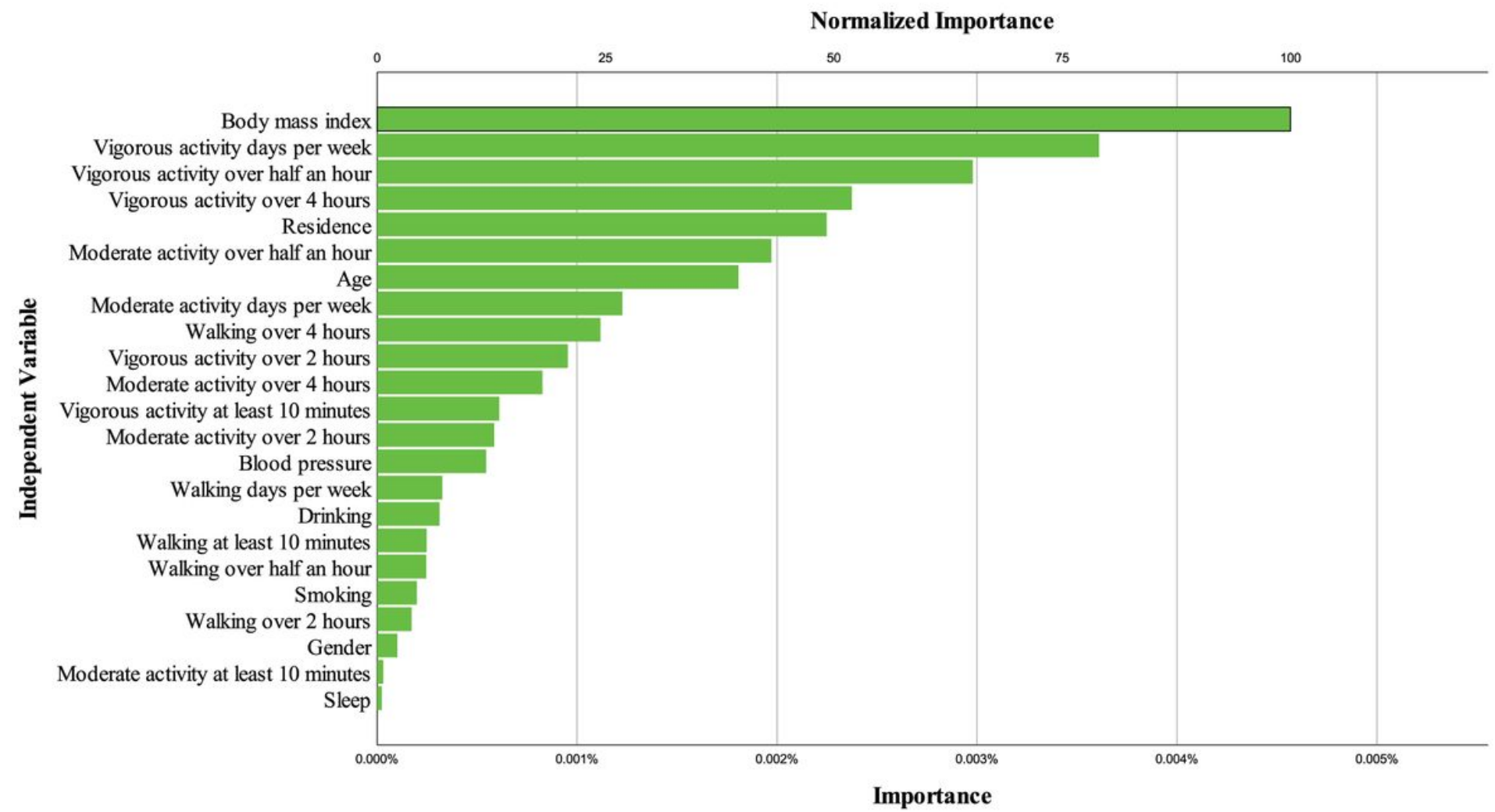

Figure 1

Variable importance on prevention of dyslipidemia.

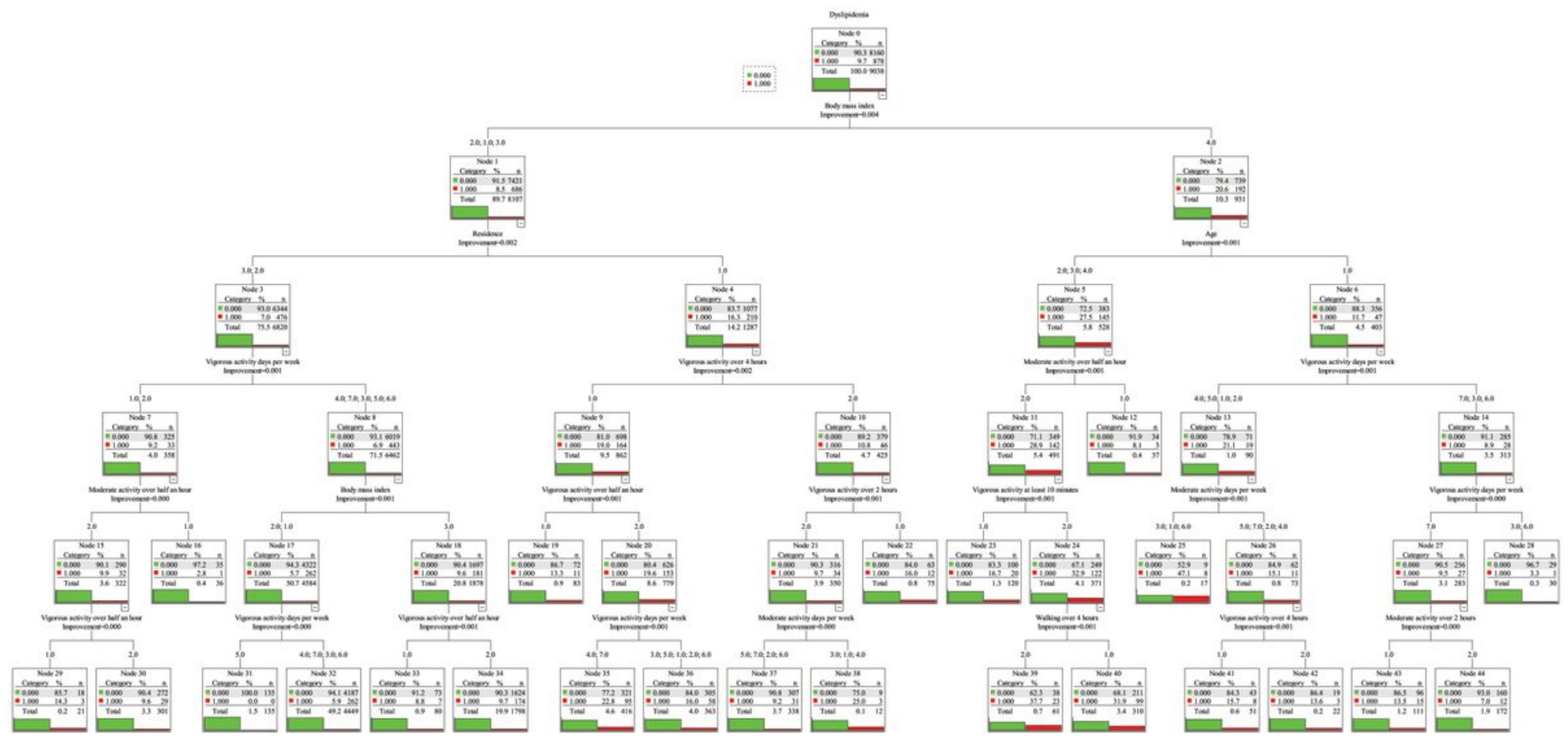




\section{Figure 2}

The structure of the decision tree model. Red categories indicate the prevalence of dyslipidemia and green categories indicate the prevalence of no dyslipidemia; Age (1: 45-54, 2: 55-64, 3: 65-74, 4: $\geq 75)$; Residence (1: Main city zone, 2: Other, 3: Village); Gender (1: Male, 2: Female); BMI (1: $<18.5 \mathrm{~kg} / \mathrm{m} 2,2$ : $18.5-23.9 \mathrm{~kg} / \mathrm{m} 2,3: 24-27.9 \mathrm{~kg} / \mathrm{m} 2,4: \geq 28 \mathrm{~kg} / \mathrm{m} 2$ ); Blood pressure (1: Normal BP, 2: Elevated BP, 3 : High BP/Stage 1, 4: High BP/Stage 2); Vigorous/moderate/light activity at least 10 minutes, vigorous/moderate/light activity over half an hour/2 hours/4 hours one day (1: Yes, 2: No); Drinking frequency (1: Never, 2: $<1 /$ month 3: $>1 /$ month); Sleep duration (1: $<7$ hours, 2: 7-10 hours, 3: $\geq 10$ hours). 